\title{
BunNerdoby open Incidence of idiopathic intracranial hypertension in Southern Tasmania, Australia
}

\author{
Natasha Krishnadas (D) , ${ }^{1}$ Bruce Taylor ${ }^{1,2}$
}

To cite: Krishnadas N, Taylor B. Incidence of idiopathic intracranial hypertension in Southern Tasmania, Australia. BMJ Neurology Open 2021;3:e000145. doi:10.1136/ bmino-2021-000145

Received 28 February 2021 Accepted 01 June 2021

\section{Check for updates}

(c) Author(s) (or their employer(s)) 2021. Re-use permitted under CC BY-NC. No commercial re-use. See rights and permissions. Published by BMJ.

${ }^{1}$ Department of Neurology, Royal Hobart Hospital, Hobart, Tasmania, Australia

${ }^{2}$ Menzies Institute for Medical Research, The University of Tasmania, Hobart, Tasmania, Australia

Correspondence to

Dr Bruce Taylor;

bruce.taylor@utas.edu.au

\begin{abstract}
Introduction Anecdotally, the incidence of idiopathic intracranial hypertension (IIH) is increasing, linked to an increase in the obesity rate in Australian society. However, formal incidence and prevalence studies are rare. We therefore sought to determine the incidence and clinical features of IIH in Southern Tasmania, Australia.

Method Neurology discharge summaries and lumbar puncture referrals from the single tertiary referral centre in this region were screened for an IIH diagnosis. All regional neurologists were surveyed to capture patients diagnosed through private neurology clinics. A retrospective review of medical records was conducted to confirm the diagnosis and determine whether patients met the Modified Dandy Criteria (MDC). Patients were included if they were above the age of 18 years and received a new diagnosis of $\mathrm{IIH}$ between June 2016 and June 2018. Population statistics were obtained from the Australian Bureau of Statistics. Results IIH incidence was 5.4/100 000. All patients were females, aged between 18 and 45 years. Headache was the most commonly reported symptom, with high rates of pre-existing or concurrent migraine diagnoses. Weight loss and commencement of oral acetazolamide were the most common treatment approaches. Four patients were medically refractory and required surgical intervention. Conclusion The incidence of $\mathrm{IH}$ in Southern Tasmania is comparable with the incidence reported in subgroups of females of childbearing age in recent prior studies. The demographic, diagnostic and therapeutic data presented can inform future local health service provision and serve as a baseline for ongoing assessment of change in incidence and treatment of $\mathrm{IH}$ at a community level.
\end{abstract}

\section{INTRODUCTION}

Idiopathic intracranial hypertension (IIH) is a condition resulting from elevated intracranial pressure in the absence of both abnormal neuroimaging and abnormal cerebrospinal fluid (CSF) composition. Diagnosis is based on the Modified Dandy Criteria (MDC). ${ }^{1}$ Headache is the most commonly cited symptom of IIH; other classical symptoms include visual obscurations, pulsatile tinnitus, photopsia, retrobulbar eye pain and visual loss. ${ }^{2}$ Papilloedema is a characteristic finding on examination, although cases without papilloedema are infrequently reported. ${ }^{3}$
While neuroimaging may identify supportive features of $\mathrm{IIH}^{45}{ }^{5}$ its utility is primarily in the exclusion of alternative causes of raised intracranial pressure.

IIH has a clear association with obesity, predominantly in young women, ${ }^{6}$ with higher incidence rates of IIH seen in this group. A subset of patients have a familial preponderance, although the mechanism of this association is unclear. ${ }^{78} \mathrm{~A}$ complex interplay also exists between IIH, migraine ${ }^{9} 10$ and other headache classifications, with over two-thirds of patients with an IIH diagnosis receiving a subsequent additional headache diagnosis, where headache persists despite treatment of IIH. ${ }^{11}$ Management strategies include weight loss (with evidence for bariatric surgery over community weight management alone), ${ }^{12}$ often in conjunction with carbonic anhydrase inhibitors (oral acetazolamide ${ }^{13}$ and/ or topiramate) and in some cases, diuretics. Patients who are medically refractory or unable to tolerate these medications may need to undergo optic nerve sheath fenestration or insertion of a CSF shunt (ventriculoperitoneal or lumboperitoneal). Intracranial venous stenting is a novel technique under investigation.

IIH can be associated with substantial morbidity, particularly if unrecognised. IIH can result in visual loss, fulfilling the WHO's definition of blindness, with previous studies identifying rates of up to $1 \%-2 \%$ of newly diagnosed IIH cases. ${ }^{14}$ IIH has been found to affect vision-specific and overall quality of life, even in those with mild visual impairment. ${ }^{15}$ This may be associated with headache frequency, visual impairment, depression ${ }^{16}$ or cognitive dysfunction. ${ }^{17}$

The incidence of IIH has been reported to be approximately $0.03-2.36 / 100000$ in a recent meta-analysis, however marked heterogeneity was noted. ${ }^{6}$ There is significant regional variation in incidence, ${ }^{18-35}$ with rates from as low as $0.03 / 100000$ in $\operatorname{Japan}^{36}$ to 
3.6/100 000 in Fife (Scotland).$^{37}$ Higher incidence rates are consistently reported in women, particularly women of childbearing age, ${ }^{18-20} 222325$ 28-31 with the highest rates reported in women with obesity. ${ }^{18-2022} 263032$ In Australia, there has only been a single study reporting the prevalence of IIH to be 24.9/100 000 in Central Western New South Wales. ${ }^{38}$

We aimed to investigate the incidence of IIH in the Southern Tasmanian region of Australia. The secondary aims were to provide a descriptive summary of patient demographics, referral sources, use of current diagnostic criteria and commonly used treatment modalities in this population.

\section{METHODS}

\section{Participants}

The requirement to obtain informed consent was waived. Patients were included if they were $\geq 18$ years of age and were given a first clinical diagnosis of IIH between June 2016 and June 2018 (incidence period).

Tasmania is one of the eight Australian states and territories. During the incidence period, the Royal Hobart Hospital (RHH) was the sole tertiary referral centre for neurology in Tasmania and employed the majority of practising neurologists in Tasmania. Screening for all first diagnoses of IIH involved: (1) review of RHH Neurology Department inpatient discharge summaries; (2) review of referral diagnoses for outpatient lumbar punctures (LPs) and radiologically assisted LPs at RHH and (3) survey of neurologists in Southern Tasmania to identify patients from private clinics.

\section{Data extraction}

For patients meeting inclusion criteria, data was extracted from the Digital Medical Record at RHH by a single investigator (NK). Clinical data for patients from private clinics was also available from this source, as these patients attended RHH for their LP. Records were reviewed to determine whether patients received a diagnosis of IIH by a neurologist and to determine whether they met MDC (box 1).

\section{Descriptive epidemiology and estimation of incidence}

While the described method may have captured all newly diagnosed cases of IIH across Tasmania, it optimally captured cases within Southern Tasmania. Therefore,

\section{Box 1 Modified Dandy Griteria IIH}

Symptoms \pm signs (if present) reflect only generalised intracranial hypertension or papilloedema.

- Elevated cerebrospinal fluid (CSF) pressure $\left(>25 \mathrm{~cm} \mathrm{H}_{2} 0\right)$ in the lateral decubitus position, with otherwise normal CSF composition.

- No evidence of a structural cause of raised intracranial pressure on neuroimaging (MRI or contrast-enhanced $\mathrm{CT}$, if the presentation is typical, or MRI+MR venography for all other patients).

- No alternative cause of raised intracranial pressure identified descriptive epidemiology is provided for the whole cohort. However, for accuracy of the incidence calculation, we stratified patients by postcode. Only patients residing within Southern Tasmania (ie, the Greater Hobart Statistical Region, defined by the Australian Bureau of Statistics) were included in the incidence calculation. The population of this statistically defined region was 229260 between July 2016-June 2017 and 232691 between July 2017-June 2018.

\section{Patient and public involvement}

Patients with IIH and the public were not involved in setting the research question or the outcome measures.

\section{RESULTS}

During the incidence period, 43 patients were given a first diagnosis of IIH by a neurologist and 29/43 (67\%) resided within the Greater Hobart Statistical region. Of these patients, 25/29 met the MDC (figure 1). One patient did not fulfil criteria due to the lack of neuroimaging (MRI or CT), while three patients had a CT brain, but contrast was not administered. Table 1 describes the characteristics of the cohort.

\section{Incidence of IIH}

Incidence of IIH within the Greater Hobart Statistical region for patients who received a diagnosis by a neurologist was $6.3 / 100000$, while the incidence for patients who met the MDC was 5.4/100000.

\section{Referral sources and common symptoms}

Figure 2 outlines the referral sources to neurology services, while figure 3 demonstrates the frequency of reported symptoms.

\section{Optometry and ophthalmology assessments}

Limited information from optometry and ophthalmology assessments at the time of diagnosis was available for $41 / 43$ patients. Papilloedema was present in $85 \%$ of cases (Frisén grade not available). Nine patients were reported to have a visual field defect (of 24 patients for whom information was available); six had patchy central vision loss or an enlarged blind spot, two had subtle bitemporal defects and one was described as having a constricted visual field. One patient had diplopia (without ophthalmoplegia) and one patient had an identifiable sixth nerve palsy at diagnosis.

\section{Lumbar puncture}

LPs were performed in the lateral decubitus position. Mean CSF opening pressure was $35 \pm 9 \mathrm{cmH}_{2} \mathrm{O}$ with wide variation in volume drained. In the 2-year study period, $58 \%$ of patients required more than one LP (one repeat LP, $\mathrm{n}=15$; two or more repeat LPs, $\mathrm{n}=10)$; 13 (30\%) patients required one or more radiologically guided LP; and 1 patient had an LP under general anaesthetic (opening pressure $58 \mathrm{cmH}_{2} \mathrm{O}$ in patient with typical features). 


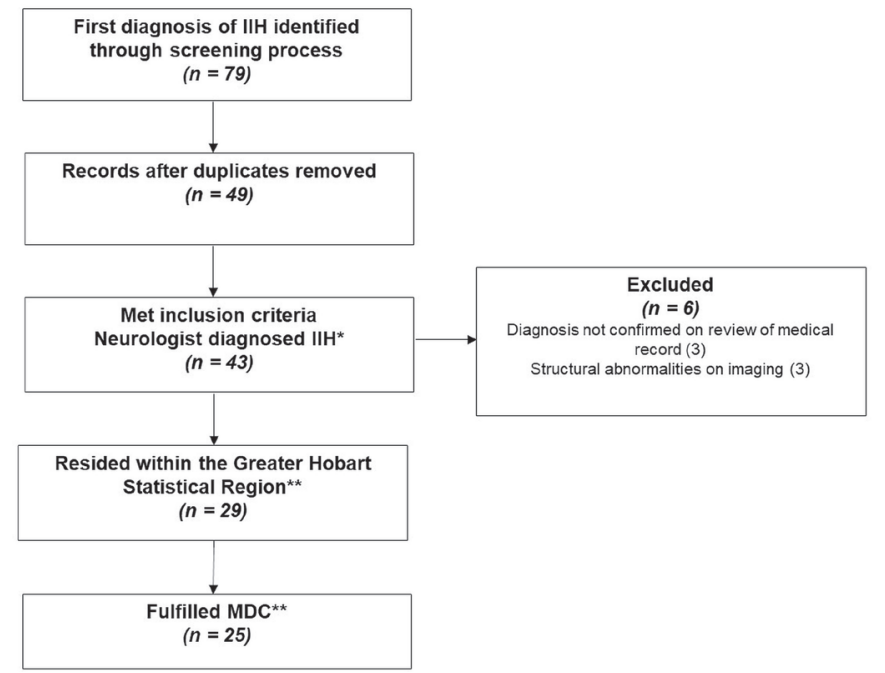

Figure 1 Case identification process. *Descriptive epidemiology is provided for all patients who met the inclusion criteria and were given a first diagnosis of $\mathrm{IIH}$ by a neurologist $(n=43)$. ${ }^{* *}$ Incidence is calculated only for patients who resided within the greater Hobart statistical region, based on (1) diagnosis made by a neurologist $(n=29)$; and (2) diagnosis fulfilling MDC $(n=25)$. IIH, idiopathic intracranial hypertension; MDC, Modified Dandy Criteria.

\section{Neuroimaging}

Supportive features of IIH were documented for 19/37 patients who had an MRI brain. A partially empty sella turcica was the most common finding. Other common features included thickened optic nerve sheaths, prominence of CSF around the optic nerves and posterior flattening of the globes. Two of the four patients who had a non-contrast CT brain instead of MRI had supportive features of IIH. Dedicated MR venogram or assessment of flow voids on MRI brain was performed in 24/37 cases with seven patients reported to have anatomical variations

Table 1 Demographics and characteristics of the cohort

\begin{tabular}{lcc}
\hline & $\begin{array}{l}\text { All patients } \\
\mathbf{n}=\mathbf{4 3}\end{array}$ & $\begin{array}{l}\text { Patients within the } \\
\text { Greater Hobart } \\
\text { Statistical region } \\
\mathbf{n}=\mathbf{2 9}\end{array}$ \\
\hline Age (years) & $27.9(8.4)$ & $27.5(8.2)$ \\
\hline Sex, $\mathrm{F}$ & $43(100 \%)$ & $29(100 \%)$ \\
\hline Weight (kg) & $111.3(22.4)^{\star}$ & $113.4(23.6) \dagger$ \\
\hline Pregnant & $1(2.3 \%)$ & $1(3.4 \%)$ \\
\hline Positive family history & $1(2.3 \%)$ & $1(3.4 \%)$ \\
\hline History of migraines & $20(46.5 \%)$ & $12(41.4 \%)$ \\
\hline Existing diagnosis & $13(30.2 \%)$ & $8(27.6 \%)$ \\
\hline New diagnosis & $7(16.3 \%)$ & $4(113.8 \%)$ \\
\hline Neurologist diagnosis & $43(100 \%)$ & $29(100 \%)$ \\
\hline MDC diagnosis & $36(83.7 \%)$ & $25(86.2 \%)$ \\
\hline
\end{tabular}

Mean (SD), unless otherwise specified.

*Data only available for $20 / 43$ patients.

†Data only available for $16 / 29$ patients.

MDC, Modified Dandy Criteria.

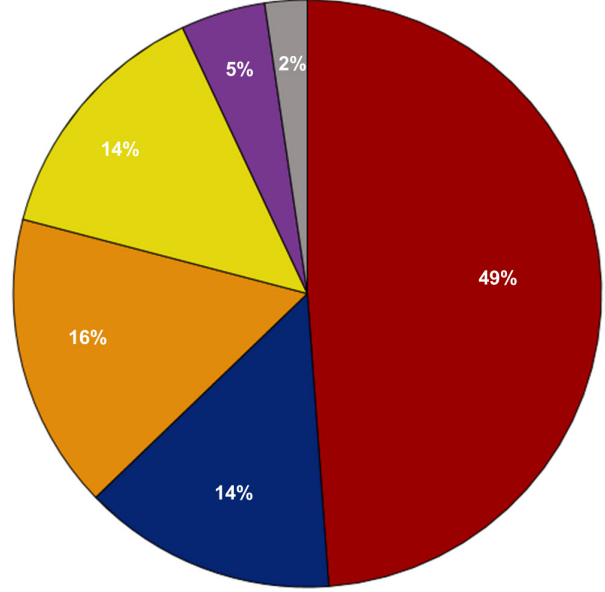

Referral source Ophthalmology Optometry General Practice Emergency Department Neurosurgery Neurology

Figure 2 Sources of referral to neurology services.

of the dural venous sinuses. These variations included small calibre sinuses, dominant or hypoplastic transverse sinuses and narrowing of the transverse sinuses.

\section{Medication use}

One patient who took tetracycline in the 12 months prior to diagnosis was not included in the calculation of incidence. One patient was taking iron supplementation (suggestive of mild iron deficiency anaemia) and one patient was on lithium. Nine patients were on the contraceptive pill (combined oral contraceptive pill $\mathrm{n}=$ 7 , progesterone-only pill $\mathrm{n}=2$ ) and 12 patients were using alternative forms of contraception (eight contraceptive implants, two intrauterine devices and two injectables). Other medications of note included: antihypertensives $(n=5)$, methotrexate $(n=2)$, antidepressants $(n=13)$, antipsychotics $(n=3)$ and thyroid replacement therapy $(n=3)$.

\section{Clinical management}

The common non-pharmacological, pharmacological and neurointerventional approaches to the management of IIH in this cohort are described in table 2.

\section{DISCUSSION}

The primary aim of this study was to investigate the incidence of IIH in Southern Tasmania, Australia. We estimate the incidence of IIH to be 5.4/100 000 for patients that

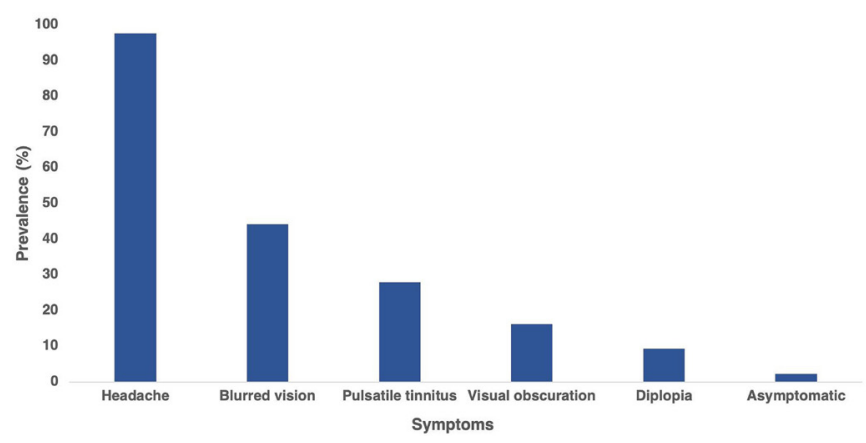

Figure 3 Prevalence of reported symptoms in patients diagnosed with idiopathic intracranial hypertension. 
Table 2 Approaches to the management of IIH

Frequency of recommendation

( $n=43), n(\%)$

\begin{tabular}{|lc}
\hline Non-pharmacological approaches & \\
\hline Weight reduction & $30(70)$ \\
\hline Dietitian review & $7(16)$ \\
\hline Sleep study referral & $6(14)$ \\
\hline Bariatric surgical referral & $5(12)^{\star}$ \\
\hline Weight reduction clinic referral & $2(5)$ \\
\hline Sodium restriction & - \\
\hline Pharmacological approaches & \\
\hline Acetazolamide (first-line) & $40(93)$ \\
\hline Topiramate & $20(47) \dagger$ \\
\hline Furosemide & $3(7)$ \\
\hline Adjunctive headache therapies & $12(28) \ddagger$ \\
\hline Neurointerventional approaches & \\
\hline Ventriculoperitoneal shunt insertion & $3(7)$ \\
\hline Intracranial venous stent & $1(2)$ \\
\hline Optic nerve sheath fenestration & - \\
\hline
\end{tabular}

*Gastric banding, $n=2$; gastric sleeve, $n=1$; gastric bypass, $n=1$, declined referral, $n=1$; two patients had gastric bypass surgery prior their IIH diagnosis.

†Predominantly second-line therapy or for patients with concurrent migraine diagnoses.

†Prescription: pre-dated IIH diagnosis, $n=6$; started following $\mathrm{IIH}$ diagnosis, $n=4$; pre-existing and ongoing prescription, $n=2$. $\mathrm{IIH}$, idiopathic intracranial hypertension.

fulfilled MDC. This is markedly higher than the incidence of IIH reported in international studies conducted within the last decade, but is comparable to incidence rates for subgroups of females of childbearing age $e^{18-20} 222325$ 28-31 (table 3). This is reflective of the fact that all patients newly diagnosed with IIH in this study were females and aged between 18 and 45 years. Despite methodological differences between studies, the incidence of IIH appears to be increasing. While improved access to diagnostics may be contributory, the increase in the incidence of IIH is occurring in parallel to increasing rates of obesity. ${ }^{6}$

In this study, the majority of patients who were given a diagnosis of IIH by a neurologist met the MDC as outlined by Friedman and Jacobson. ${ }^{1}$ In a handful of cases, criteria were not met owing to the lack of neuroimaging (MRI brain or contrast-enhanced CT brain). It should be noted that the MDC have been revised by Friedman et al. ${ }^{39}$ While the two versions are similar, the main difference is that, for a diagnosis of IIH, the updated criteria require patients who fit the typical demographic for IIH to have an MRI brain with and without gadolinium, and all other patients to have an MRI with and without gadolinium plus MR venogram. ${ }^{39}$ As patients in this cohort did not consistently have gadolinium administered, we have used the earlier iteration of the MDC. ${ }^{1}$ In contrast to current criteria, the earliest criteria described by Smith ${ }^{40}$ did not stipulate the need for an MRI brain or contrast-enhanced
CT for diagnosis. Therefore, we have opted to report incidence as a function of a neurologists' clinical diagnosis (lenient criteria) and as a function of the MDC published in $2002^{1}$ (stringent criteria), while acknowledging that the lack of contrast-enhanced imaging precludes a diagnosis of MDC according to the latest 2013 criteria in this cohort. $^{39}$

Some medications and medical conditions have been linked with raised intracranial pressures, ${ }^{41}$ but there remains debate as to the strength of these associations. One patient with long-term use of tetracycline was not included in the incidence calculation, due to the probable association between tetracycline and the development of intracranial hypertension. ${ }^{41}$ However, patients taking other medications such as lithium and one patient with mild iron deficiency anaemia were still included in case numbers fulfilling MDC due to the weaker associations. ${ }^{41}$ The high prevalence of contraceptive use (including the oral contraceptive pill, OCP) and antidepressants in this study likely reflects their common use in the general population. While a previous case series reported OCP use in $24 \%$ of IIH patients, ${ }^{27}$ a case-control study comparing patients with IIH to age, sex and body mass index-matched patients did not find a significant association between OCP use and IIH. ${ }^{42}$

Headache was the most commonly reported symptom. Consistent with prior literature, we have identified the co-occurrence of IIH and either pre-existing or subsequent headache diagnoses, in particular, migraine. ${ }^{11}$ It has been proposed that a link exists between IIH and migraine, triggered by either collapse or congestion of the venous sinuses, resulting in an increase in nociceptive pain, thereby aggravating migraine. ${ }^{9}{ }^{10}$ Supportive neuroimaging features described in this study correspond with previous literature on $\mathrm{IIH}^{45}$

The majority of referrals to neurology services for the assessment of IIH were received from ophthalmologists and optometrists, followed by referrals from general practitioners and the emergency department. An awareness of the increasing incidence and the potential for significant morbidity of IIH, particularly if undiagnosed, should prompt early referral to both neurology and ophthalmology services. The use of MRI and CT brain in the MDC criteria and the frequent need for radiologically guided LPs for IIH should prompt health services and radiology departments to assess their capacity to manage this potential gradual increase in demand for services. The clear association between obesity and IIH may also warrant consideration of a centralised service to facilitate intensive weight reduction and create a streamlined referral pathway for bariatric surgery. A coordinated multidisciplinary approach involving neurologists, ophthalmologists, dieticians, bariatric services, endocrinologists, radiologists, neurosurgeons and interventionalists may yield improved outcomes.

The main strength of this study was the robust ability to screen for all newly diagnosed cases of IIH within the incidence period. As the RHH was the sole tertiary referral 
Table 3 Reported incidence rates of IIH worldwide

\begin{tabular}{|c|c|c|c|c|c|}
\hline Region & Year(s) of study & $\begin{array}{l}\text { Incidence per } \\
100000\end{array}$ & $\begin{array}{l}\text { Incidence in } \\
\text { females }\end{array}$ & $\begin{array}{l}\text { Incidence in females } \\
\text { of childbearing age }\end{array}$ & $\begin{array}{l}\text { Incidence in } \\
\text { females with } \\
\text { obesity }\end{array}$ \\
\hline US $(\text { lowa })^{18}$ & 1984-1985 & 0.9 & & 3.5 & 13 \\
\hline Libya (Benghazi) $^{19}$ & $1982-1989$ & 2.2 & 4.3 & 12 & 21.4 \\
\hline US (Minnesota) ${ }^{20}$ & $1976-1990$ & 0.98 & 1.6 & 3.3 & 7.9 \\
\hline Northern Ireland ${ }^{21}$ & 1991-1995 & 0.5 & 0.9 & & \\
\hline Italy $y^{22}$ & 1990-1999 & 0.28 & & 0.65 & 2.7 \\
\hline$\left.\right|_{\text {srael }} ^{23}$ & 1998-1999 & $0.57-0.94$ & 1.82 & 4.02 & \\
\hline Spain (Valladolid) ${ }^{24}$ & 1994-2004 & 3.2 & & & \\
\hline$\left.\left.\right|_{\text {srael| }}\right|^{25}$ & 2005-2007 & 2.02 & 3.17 & 5.49 & \\
\hline Sweden (Stockholm) ${ }^{29}$ & 2006-2013 & 0.65 & 1.1 & 1.96 & \\
\hline US (Minnesota) ${ }^{30}$ & 1990-2014 & 1.8 & 3.3 & 6.8 & 22 \\
\hline Northern Ireland ${ }^{31}$ & $2007-2014$ & 2.36 & 4.65 & 9.85 & \\
\hline Scotland (Fife) $)^{37}$ & 2013-2014 & 3.56 & & & \\
\hline $\mathrm{USA}^{33}$ & $1997-2016$ & 1.15 & 1.97 & & \\
\hline $\mathrm{UK}^{34}$ & 2002-2016 & $\begin{array}{l}2.3(2002) \\
4.7(2016)\end{array}$ & & & \\
\hline Scotland $^{32}$ & 2016-2017 & 2.65 & & & 37.9 \\
\hline Kuwait $^{35}$ & 2018 & 3.28 & & & \\
\hline
\end{tabular}

$\mathrm{IIH}$, idiopathic intracranial hypertension.

centre for neurology in Tasmania and the majority of neurologists in Tasmania were employed by this hospital service during the incidence period, we can be confident that the cases of IIH captured within the Greater Hobart Statistical region are an accurate reflection of the number of new cases. We have not used the whole sample to calculate incidence, as we cannot exclude that patients from regions external to the Greater Hobart Statistical region did not seek treatment from other hospital services, visiting neurologists, non-neurologist physicians or ophthalmologists. Additionally, we cannot exclude the possibility that there are asymptomatic patients in the community that have not come to medical attention.

This study offers a snapshot in time. All patients diagnosed with IIH in this study are females of childbearing age. While this is consistent with the 'typical' demographics of patients with this condition, this may not be generalisable to the Australian population at large. As this study involved retrospective review of the medical record, the descriptive epidemiology provided may be an under-representation of the level of detail of the clinical assessments made and management plans instituted. Future studies should consider adopting a prospective longitudinal approach, following best practice diagnostic and treatment guidelines.

\section{CONCLUSION}

The incidence of IIH in Southern Tasmania, Australia, was 5.4/100 000, which is comparable to the incidence reported for subgroups of females of childbearing age in prior studies conducted within the last decade. The findings in this study support the need to increase awareness of this condition and consider a coordinated multidisciplinary approach to the care of patients with IIH. While prospective longitudinal studies are ongoing regarding pharmacological therapies, further studies are also needed to determine the best approaches to IIH diagnosis and care provision, to optimise long-term outcomes.

Acknowledgements The authors acknowledge Drs Dean Jones, Helen Castley, Dale Sebire, Jennifer MacIntyre, Michael Dreyer, Sarah Hewer, Lucy Aldous, as well as the Department of Radiology and Ambulatory Care Centre staff at the Royal Hobart Hospital for their assistance with facilitating data collection.

Contributors NK contributed to data acquisition, statistical analysis and wrote the manuscript. BT contributed to the conception of the study and edited the manuscript. 
Funding This study was supported by the Department of Neurology, Royal Hobart Hospital, Tasmania, Australia (grant number not applicable).

Competing interests None.

Patient consent for publication Not required.

Ethics approval The University of Tasmania Human Ethics Committee approved this study

Provenance and peer review Not commissioned; externally peer reviewed.

Data availability statement All data relevant to the study are included in the article or uploaded as supplementary information.

Open access This is an open access article distributed in accordance with the Creative Commons Attribution Non Commercial (CC BY-NC 4.0) license, which permits others to distribute, remix, adapt, build upon this work non-commercially, and license their derivative works on different terms, provided the original work is properly cited, appropriate credit is given, any changes made indicated, and the use is non-commercial. See: http://creativecommons.org/licenses/by-nc/4.0/.

\section{ORCID iD}

Natasha Krishnadas http://orcid.org/0000-0002-5374-2839

\section{REFERENCES}

1 Friedman DI, Jacobson DM. Diagnostic criteria for idiopathic intracranial hypertension. Neurology 2002;59:1492-5.

2 Wall M. Idiopathic intracranial hypertension. Neurol Clin 2010;28:593-617.

3 Digre KB, Nakamoto BK, Warner JEA, et al. A comparison of idiopathic intracranial hypertension with and without papilledema. Headache 2009;49:185-93.

4 Yuh WT, Zhu M, Taoka T, et al. MR imaging of pituitary morphology in idiopathic intracranial hypertension. J Magn Reson Imaging 2000;12:808-13.

5 Bidot S, Saindane AM, Peragallo $\mathrm{JH}$, et al. Brain imaging in idiopathic intracranial hypertension. J Neuroophthalmol 2015;35:400-11.

6 McCluskey G, Doherty-Allan R, McCarron P, et al. Meta-analysis and systematic review of population-based epidemiological studies in idiopathic intracranial hypertension. Eur J Neurol 2018;25:1218-27.

7 Klein A, Dotan G, Kesler A. Familial occurrence of idiopathic intracranial hypertension. Isr Med Assoc J 2018;20:557-60.

8 Corbett JJ. The first Jacobson lecture. Familial idiopathic intracranial hypertension. J Neuroophthalmol 2008;28:337-47.

9 De Simone R, Ranieri A, Fiorillo C, et al. Is idiopathic intracranial hypertension without papilledema a risk factor for migraine progression? Neurol Sci 2010;31:411-5.

10 De Simone R, Ranieri A. The role of intracranial hypertension in the chronification of migraine. Neurol Sci 2015;36:23-8.

11 Friedman DI, Rausch EA. Headache diagnoses in patients with treated idiopathic intracranial hypertension. Neurology 2002:58:1551-3.

12 Mollan SP, Mitchell JL, Ottridge RS, et al. Effectiveness of bariatric surgery vs community weight management intervention for the treatment of idiopathic intracranial hypertension: a randomized clinical trial. JAMA Neurol 2021. doi:10.1001/jamaneurol.2021.0659. [Epub ahead of print: 26 Apr 2021].

13 NORDIC Idiopathic Intracranial Hypertension Study Group Writing Committee, Wall M, McDermott MP, et al. Effect of acetazolamide on visual function in patients with idiopathic intracranial hypertension and mild visual loss: the idiopathic intracranial hypertension treatment trial. JAMA 2014;311:1641-51.

14 Best J, Silvestri G, Burton B, et al. The incidence of blindness due to idiopathic intracranial hypertension in the UK. Open Ophthalmol $J$ 2013;7:26-9.

15 Digre KB, Bruce BB, McDermott MP, et al. Quality of life in idiopathic intracranial hypertension at diagnosis: $\mathrm{IH}$ treatment trial results. Neurology 2015;84:2449-56.

16 Raggi A, Marzoli SB, Chiapparini L, et al. Headache frequency and symptoms of depression as predictors of disability in patients with idiopathic intracranial hypertension. Neurol Sci 2018;39:139-40.

17 Yri HM, Fagerlund B, Forchhammer HB, et al. Cognitive function in idiopathic intracranial hypertension: a prospective case-control study. BMJ Open 2014;4:e004376.
18 Durcan FJ, Corbett JJ, Wall M. The incidence of pseudotumor cerebri. Population studies in lowa and Louisiana. Arch Neurol 1988;45:875-7.

19 Radhakrishnan K, Thacker AK, Bohlaga NH, et al. Epidemiology of idiopathic intracranial hypertension: a prospective and case-control study. J Neurol Sci 1993;116:18-28.

20 Radhakrishnan K, Ahlskog JE, Cross SA, et al. Idiopathic intracranial hypertension (pseudotumor cerebri). Descriptive epidemiology in Rochester, Minn, 1976 to 1990. Arch Neurol 1993:50:78-80.

21 Craig JJ, Mulholland DA, Gibson JM. Idiopathic intracranial hypertension; incidence, presenting features and outcome in Northern Ireland (1991-1995). Ulster Med J 2001;70:31-5.

22 Carta A, Bertuzzi F, Cologno D, et al. Idiopathic intracranial hypertension (pseudotumor cerebri): descriptive epidemiology, clinical features, and visual outcome in Parma, Italy, 1990 to 1999. Eur J Ophthalmol 2004;14:48-54.

23 Kesler A, Gadoth N. Epidemiology of idiopathic intracranial hypertension in Israel. J Neuroophthalmol 2001;21:12-14.

24 Asensio-Sánchez VM, Merino-Angulo J, Martínez-Calvo S, et al. Epidemiología del pseudotumor cerebral. Arch Soc Esp Oftalmol 2007;82:219-21.

25 Kesler A, Stolovic N, Bluednikov Y, et al. The incidence of idiopathic intracranial hypertension in Israel from 2005 to 2007: results of a nationwide survey. Eur J Neurol 2014;21:1055-9.

26 Raoof N, Sharrack B, Pepper IM, et al. The incidence and prevalence of idiopathic intracranial hypertension in Sheffield, UK. Eur J Neurol 2011:18:1266-8.

27 Contreras-Martin Y, Bueno-Perdomo JH. Idiopathic intracranial hypertension: descriptive analysis in our setting. Neurologia 2015;30:106-10.

28 Idiculla T, Zachariah G, Br K, et al. The incidence and prevalance of idiopathic intracranial hypertension in south Sharaqiah region, Oman. Oman J Ophthalmol 2013;6:189-92.

29 Sundholm A, Burkill S, Sveinsson O, et al. Population-based incidence and clinical characteristics of idiopathic intracranial hypertension. Acta Neurol Scand 2017;136:427-33.

30 Kilgore KP, Lee MS, Leavitt JA, et al. Re-evaluating the incidence of idiopathic intracranial hypertension in an era of increasing obesity. Ophthalmology 2017;124:697-700.

31 McCluskey G, Mulholland DA, McCarron P, et al. Idiopathic intracranial hypertension in the northwest of Northern Ireland: epidemiology and clinical management. Neuroepidemiology 2015;45:34-9.

32 Goudie C, Shah P, McKee J, et al. The incidence of idiopathic intracranial hypertension in Scotland: a SOSU study. Eye 2019;33:1570-6.

33 Ghaffari-Rafi A, Mehdizadeh R, Ko AWK, et al. Idiopathic intracranial hypertension in the United States: demographic and socioeconomic disparities. Front Neurol 2020;11:869.

34 Mollan SP, Aguiar M, Evison F, et al. The expanding burden of idiopathic intracranial hypertension. Eye 2019;33:478-85.

35 Al-Hashel JY, Ismail II, Ibrahim M, et al. Demographics, clinical characteristics, and management of idiopathic intracranial hypertension in Kuwait: a single-center experience. Front Neurol 2020;11:672.

36 Yabe I, Moriwaka F, Notoya A, et al. Incidence of idiopathic intracranial hypertension in Hokkaido, the northernmost island of Japan. J Neurol 2000;247:474-5.

37 Goudie C, Burr J, Blaikie A. Incidence of idiopathic intracranial hypertension in Fife. Scott Med J 2019;64:62-6.

38 Lichentenberg I, Blackwood E, Gordon J. The prevalence of idiopathic intracranial hypertension and associated co-morbidities in central Western New South Wales. J Neurol Neurosurg Psychiatry 2017;88:e1.

39 Friedman DI, Liu GT, Digre KB. Revised diagnostic criteria for the pseudotumor cerebri syndrome in adults and children. Neurology 2013;81:1159-65.

40 Smith JL. Whence pseudotumor cerebri? J Clin Neuroophthalmol 1985:5:55-6.

41 Chen J, Wall M. Epidemiology and risk factors for idiopathic intracranial hypertension. Int Ophthalmol Clin 2014;54:1-11.

42 Kilgore KP, Lee MS, Leavitt JA, et al. A population-based, case-control evaluation of the association between hormonal contraceptives and idiopathic intracranial hypertension. $A m \mathrm{~J}$ Ophthalmol 2019;197:74-9. 